\title{
Internal Stress Formation and Changes in Oxide Films on a Lead Alloy Anode Surface
}

\author{
Jianzhong $\mathrm{Li}^{1,2, *}$, Yunkai Wang ${ }^{1,2}$, Ying $\mathrm{Bi}^{1,2}$, Ying $\mathrm{Li}^{1,2}$, Yanwen Tian ${ }^{1,2}$ \\ ${ }^{1}$ School of Metallurgy, Northeastern University, Shenyang 110819, China \\ ${ }^{2}$ Liaoning Key Laboratory for Metallurgical Sensors and Technology, Northeastern University, \\ Shenyang 110819, China \\ *E-mail: lijz@smm.neu.edu.cn
}

doi: $10.20964 / 2016.12 .07$

Received: 26 July 2016 / Accepted: 21 September 2016 / Published: 10 November 2016

\begin{abstract}
Internal stresses significantly influence the mechanical, structural, and electrochemical performance of oxide films on lead alloy substrates. In this study, internal stress formation and changes on oxide films formed in situ on a lead anode surface were evaluated with Raman spectroscopy. The results showed that stress changes were highly dependent upon the morphology and phase composition of the oxide film, as determined by scanning electron microscopy and $\mathrm{X}$-ray diffraction. $\mathrm{PbO} / \mathrm{PbO}_{2}$ films generated in the chromium(VI) electrolyte obviously induced compressive stress in the initial oxidation stage, followed by tensile stress. However, $\mathrm{PbO} / \mathrm{PbO}_{2}$ films obtained using $\mathrm{SO}_{4}{ }^{2-}$ and $\mathrm{Cl}^{-}$electrolytes were attributed to the influence tensile stress over the entire oxidation time. $\mathrm{PbCrO}_{4}$ and $\mathrm{PbSO}_{4}$ films compositions contributed to the development of compressive stress. The coupling of changes in compressive and tensile stresses on oxide films tended to generate microcracks, leading to an increase in the electrical conductivity of the films.
\end{abstract}

Keywords: Internal stresses; lead substrate; anode; oxide films; oxidation

\section{$\underline{\text { FULL TEXT }}$}

(C) 2016 The Authors. Published by ESG (www.electrochemsci.org). This article is an open access article distributed under the terms and conditions of the Creative Commons Attribution license (http://creativecommons.org/licenses/by/4.0/). 